\title{
Diffusion Tensor Tractography Characteristics of White Matter Tracts are Associated with Post-Stroke Depression
}

This article was published in the following Dove Press journal: Neuropsychiatric Disease and Treatment

\author{
Lijun Deng' \\ Rubo Sui' \\ Lei Zhang ${ }^{2}$ \\ 'Department of Neurology, First \\ Affiliated Hospital of Jinzhou Medical \\ University, Jinzhou, Liaoning, People's \\ Republic of China; ${ }^{2}$ School of Nursing, \\ Jinzhou Medical University, Jinzhou, \\ Liaoning, People's Republic of China
}

Purpose: To analyze the changes in white matter tracts in patients with post-stroke depression (PSD), and the correlation between these changes and the depressive state.

Patients and Methods: The numbers of white matter tracts and corresponding fractional anisotropy (FA) in the acute phase (the onset time $<72$ hours) were examined in each subject by diffusion tensor tractography (DTT). Diffusion tensor imaging (DTT), a new development of diffusion tensor imaging (DTI), enables visualization of white matter fiber tracts, which are thought to be closely related to the occurrence of PSD, According to the scores of Hamilton Depression Scale (HAMD) recorded at the 2nd week, 1st month, 3rd month, 6th month, and 12th month, forty patients were randomly selected and were classified into PSD group ( $n=20$ ), non-depression post-stroke group (N-PSD, $n=20$ ), and control normal group (NORM, $n=20$ ), respectively. Correlations between the number of bundles (lines) in the white matter tract and corresponding FA, and HAMD score were finally assessed.

Results: 1) FAs of the ipsilesional crossed corticocerebellar tract, the corticospinal tract, and the anterior thalamic radiation in PSD group were significantly lower than those in N-PSD and NORM groups $(P<0.01) ; 2)$ Lines in the three areas in the PSD group were significantly lower than those in the N-PSD and NORM groups $(P<0.01)$; and 3) FA and lines in the three areas of PSD patients were negatively correlated to HAMD scores (correlation coefficient= $-0.586,-0.793,-0.626,-0.533,-0.642$, and -0.524 , respectively, all $P<0.05$ ).

Conclusion: FA and lines of the ipsilesional crossed corticocerebellar tract, the corticospinal tract, and the anterior thalamic radiation in PSD patients are significantly correlated to the depressive state. The crossed corticocerebellar tract, the corticospinal tract and the anterior thalamic radiation are involved in the development of PSD.

Keywords: post-stroke depression, white matter tracts, diffusion tensor imaging, diffusion tensor tractography

\section{Introduction}

Post-stroke depression (PSD) is secondary, always emerging as a neuropsychiatric complication in stroke patients that affects their long-term prognosis. Depression is a common complication after stroke, which can increase the mortality rate by 10 times, ${ }^{1}$ and has a negative impact on social participation, quality-of-life, and daily life ability. To date, the main therapeutic approach to PSD, particularly in the subacute phase after stroke, is essentially pharmacological. In hopes of identifying better treatment options, this may be closely related to the unclear pathogenesis of PSD. Many attempts have been made to further elucidate the mechanism of the pathological
Correspondence: Rubo Sui Department of Neurology, The First Affiliated Hospital of Jinzhou Medical University, Jinzhou, Liaoning, People's Republic of China

Tel +8613204525199

Email 627079227@qq.com

Neuropsychiatric Disease and Treatment 2021:|7 |67-|8| 
brain. Several microstructural brain abnormalities have been reported of major depressive disorder (MDD) in novel imaging techniques in vivo. ${ }^{2}$ Therefore, it is possible that mental illness is not caused by damage to a particular brain region, since PSD is a unique cognitive and affective dysfunction. Therefore, we speculate that the brain microstructure of PSD has changed. As is known, the structural integrity of the white matter fiber bundles provides the basis for abnormal brain function. ${ }^{3}$ Conventional MRI studies focus on the site of stroke but fail to identify adjacent neural structures. However, diffusion tensor fiber bundle technique is a new kind of MR. It quantifies the direction and structural integrity of the white matter fiber bundles in the neural network. As an extension of the DTI technique, DTT is a diffusionweighted pulse train sensitive to microscopic random water motion to measure water diffusion. ${ }^{4}$ If the diffusion of water is not restricted in any direction, the diffusion is called isotropy; if the mobility of water is restricted, diffusion is called anisotropy. The anisotropy score is usually used to quantify: the greater the FA value, the greater the anisotropy of the white matter fiber bundle. Axon size and density, path geometry, and fiber crossings may also be influenced by the highly organized and myelinated bundles. ${ }^{5-7}$ DTT reconstruction interested in fascicles usually adopt a joint area (combined region of interest, ROI) method. ROI areas and reconstruction conditions for each bundle are clearly defined. ${ }^{8-10}$ The reliability of DTT technique has been confirmed by some studies. ${ }^{8-10}$ We intended to analyze whether white matter tracts are altered in PSD patients and what types of fibers are involved. Moreover, a potential correlation between changes in white matter tracts and depressive state was assessed.

\section{Subjects and Methods}

\section{Patients and Grouping of Subjects}

The experimental protocol was established according to the ethical guidelines of the Helsinki Declaration, and was approved by the Ethics Committee of the First Affiliated Hospital of Jinzhou Medical University, China. Written informed consent was obtained from individual participants. This clinical trial was approved by. Data of all patients hospitalized with stroke in the basal ganglia for the first time and hospitalized in the Neurology Department, the First Affiliated Hospital of Jinzhou Medical University from September 2018 to September 2019 were recruited, and routine clinical information was collected after admission. This was according to the 21 items of HAMD-21 recorded at the 2nd week, 1st month, 3rd month, 6th month, and 12th month after stroke. Based on the scores, patients were divided into poststroke depression group and poststroke non-depression group (NPSD). The was a random selection of patients aged 40-75 years with acute ischemic stroke in the basal ganglia for the first time, including 20 PSD cases and 20 non-PSD ones. During the same period, age-matched healthy subjects $(n=20)$ were recruited in the NORM group.

\section{Inclusion and Exclusion Criteria Inclusion Criteria}

i) Acute ischemic stroke in the basal ganglia for the first time confirmed by head CT and MRI; ii) The patient was diagnosed as the first basal ganglia ischemic stroke by head CT at the onset of the disease, which met the Fourth National Diagnostic Criteria for Cerebrovascular Disease, $^{11}$ iii) According to the previous domestic and foreign literature reports. ${ }^{12,13}$ Patients with basal ganglia infarction had the highest prevalence of depression $(21 \%)$. In this study, the selected lesions were all located in the basal ganglia region. Stroke lesions were located in the basal ganglia.

\section{Exclusion Criteria}

i) Subjects with functional mental disorders, functional depression, or mental disorders caused by psychoactive substances and addictive substances; ii) Subjects with consciousness disorder, aphasia, hearing impairment, severe cognitive impairment, or those who were uncooperative to examinations; iii) Family history of serious mental diseases or neurological diseases in the firstdegree relatives of subjects; iv) Subjects with white matter lesions, cerebral hemorrhage, subarachnoid hemorrhage, cardiopulmonary failure, liver and kidney insufficiency, or end-stage diseases; and v) Subjects with contraindications of MRI.

\section{Collection of Clinical Data}

The sex, marriage, age, education, and basal ganglia infarction direction of the study subjects were recorded. Previous history of TIA, hypertension, diabetes, coronary heart disease, smoking, etc. Computed tomography (CT), electrocardiography, echocardiography, carotid artery ultrasonography, and transcranial Doppler were performed. 


\section{Evaluation Standards}

National Institutes of Health Stroke Scale (NIHSS)

Neurological impairment of stroke patients was evaluated by an experienced neurologist using the National Institutes of Health Stroke Scale (NIHSS), with each item given 3-5 levels. The score of NIHSS ranged from $0-42$, and the higher score indicated a more severe neurological impairment.

\section{Self-Rating Depression Scale (SDS)}

The Self-rating Depression Scale (SDS) was used for initial screening of depression of stroke patients, which was convenient and not influenced by age, economics, etc (non-depression, $<53$ points; depression, $\geq 53$ points) (Table 1).

\section{Hamilton Depression Scale (HAMD-2I)}

HAMD-21 was used for evaluating depression severity. It was a reliable questionnaire for assessing depression severity, guilty conscience, suicide idea, sleeping difficulty, weight loss, decline of ability, and cognitive disturbance, etc. A higher score of HAMD-21 was indicative of a more severe depression (non-depression, $<7$ points; depression, $\geq 7$ points) (Table 2 ).

\section{Mini-Mental State Examination (MMSE)}

MMSE includes items such as time, place, orientation, language, mental arithmetic, immediate and short-term auditory word memory, and structural imitation, and is considered the first choice for dementia screening. The higher the score, the better the cognitive function (Table 3).

\section{Methods}

\section{MRI and DTI Protocol}

The scans covered the whole brain, MRI was performed in each stroke patient at the acute phase by an experienced imaging specialist. No significantly abnormal signals in the brain were found on a Philips Achieva 3.0 T TX MRI scanner. DTI was performed after MRI. The patient was in the conscious state, and the head was fixed using a sponge pad and maintained in the same position during the examination. Bilateral external auditory meatuses were blocked by cotton balls. A spin-echo, echo-planar imaging sequence at an axial position was performed to obtain DTI parameters with the following settings: Repetition time $(\mathrm{TR})=6,100 \quad \mathrm{~ms}$, echo time $\quad(\mathrm{TE})=87 \mathrm{~ms}$, slice thickness $=2.5 \mathrm{~mm}$, zero-filling, the number of slices $=50$, data matrix $=128 \times 128$, filed of view (FOV)
Table I SDS

\begin{tabular}{|c|c|c|c|c|}
\hline \multirow{2}{*}{$\begin{array}{l}\text { Name: Anon; Sex: } \\
\text { Male; } \\
\text { Age: } 67 \text { years } \\
\text { Item }\end{array}$} & \multicolumn{4}{|c|}{$\begin{array}{l}\text { Profession: No } \\
\text { Cultural Level: Junior } \\
\text { Number: } \mathbf{4 8 4 5 5 3 8}\end{array}$} \\
\hline & $\begin{array}{l}\text { A Little } \\
\text { of the } \\
\text { Time }\end{array}$ & $\begin{array}{l}\text { Some } \\
\text { of the } \\
\text { Time }\end{array}$ & $\begin{array}{l}\text { Good } \\
\text { Part of } \\
\text { the } \\
\text { Time }\end{array}$ & $\begin{array}{l}\text { Most } \\
\text { of the } \\
\text { Time }\end{array}$ \\
\hline $\begin{array}{l}\text { I. I feel down-hearted } \\
\text { and blue } \\
\text { 2. Morning is when } \\
\text { I feel the best } \\
\text { 3. I have crying spells } \\
\text { or feel like it } \\
\text { 4. I have trouble } \\
\text { sleeping at night } \\
\text { 5. I eat as much as } \\
\text { I used to } \\
6 \text {.I still enjoy sex } \\
\text { 7. I notice that I am } \\
\text { losing weight } \\
\text { 8. I have trouble with } \\
\text { constipation } \\
\text { 9. My heart beats } \\
\text { faster than usual } \\
\text { I0. I get tired for no } \\
\text { reason } \\
\text { II. My mind is as clear } \\
\text { as it used to be } \\
\text { I2. I find it easy to do } \\
\text { the things I used to } \\
\text { I3. I am restless and } \\
\text { can not keep still } \\
\text { I4. I feel hopeful } \\
\text { about the future } \\
\text { I5. I am more irritable } \\
\text { than usual } \\
\text { I6. I find it easy to } \\
\text { make decisions } \\
\text { I7. I feel that I am } \\
\text { useful and needed } \\
\text { I8. My life is pretty full } \\
\text { 19. I feel that others } \\
\text { would be better off if } \\
\text { I were dead } \\
\text { 20. I still enjoy the } \\
\text { things I used to do }\end{array}$ & $\begin{array}{l}4 \\
4\end{array}$ & 2 & 3 & 4 \\
\hline Total Score & 66 & & & \\
\hline
\end{tabular}

$=256 \times 256 \mathrm{~mm}^{2}$, diffusion directions $=64, \mathrm{~b}=1,000 \mathrm{~s} / \mathrm{mm}^{2}$, $b$-value $=0$, and number of excitations $(\mathrm{NEX})=2$. Structural MRI parameters were obtained with the following settings: 
Table 2 HAMD

\begin{tabular}{|c|c|c|c|c|c|}
\hline \multirow{2}{*}{$\begin{array}{l}\text { Name:Anon; Sex: Male; } \\
\text { Age: } 67 \text { years } \\
\text { Item }\end{array}$} & \multicolumn{5}{|c|}{$\begin{array}{l}\text { Profession: No } \\
\text { Cultural Level: Junior } \\
\text { Number: } \mathbf{4 8 4 5 5 3 8}\end{array}$} \\
\hline & None & Mild & Moderate & Severe & Extremely Severe \\
\hline $\begin{array}{l}\text { 1. Depressed mood } \\
\text { 2. Guilt } \\
\text { 3. Suicide } \\
\text { 4. Insomnia, initial } \\
\text { 5. Insomnia, middle } \\
\text { 6. Insomnia, delayed } \\
\text { 7. Work and interests } \\
\text { 8. Retardation } \\
\text { 9. Agitation } \\
\text { 10. Anxiety, psychic } \\
\text { II. Anxiety, somatic } \\
\text { 12. Somatic symptoms, gastrointestinal } \\
\text { 13. Somatic symptoms, general } \\
\text { 14. Genital symptoms } \\
\text { 15. Hypochondriasis } \\
\text { 16. Loss of weight, } \\
\text { 17. Insight } \\
\text { 18. Diurnal variation } \\
\text { 19. Depersonalization and derealization } \\
\text { 20. Paranoid symptoms } \\
\text { 21. Obsessional symptoms }\end{array}$ & $\begin{array}{l}0 \\
0 \\
0 \\
0 \\
0 \\
0 \\
0 \\
0\end{array}$ & I & $\begin{array}{l}2 \\
2 \\
2 \\
2\end{array}$ & 3 & \\
\hline Total Score & 19 & & & & \\
\hline
\end{tabular}

Table 3 MMSE

\begin{tabular}{|l|l|}
\hline $\begin{array}{l}\text { Name:Anon; Sex: Male; } \\
\text { Age: } 67 \text { years }\end{array}$ & $\begin{array}{l}\text { Profession: No } \\
\text { Cultural Level: Junior } \\
\text { Number: 4845538 }\end{array}$ \\
\hline Item & Score \\
\hline I. Time orientation & 5 \\
2. Place orientation & 5 \\
3. Immediate memory & 3 \\
4. Short-term memory & 1 \\
5. Computing power & 3 \\
6. Named & 2 \\
7. Repeat & 1 \\
8. Reading comprehension & 1 \\
9. Language understanding & 3 \\
I0. Language & 0 \\
II. Visual spatial ability & 1 \\
\hline Total Score & 25 \\
\hline
\end{tabular}

The number of slices $=176, \mathrm{TR}=1,900 \mathrm{~ms}, \mathrm{TE}=3.44 \mathrm{~ms}$, slice thickness $=1 \mathrm{~mm}$, flip angle $(\mathrm{FA})=9^{\circ}$, inversion time $=900 \mathrm{~ms}, \mathrm{FOV}=256 \times 256 \mathrm{~mm}^{2}$, and acquisition matrix $=256 \times 256$. Scanning of structural MRI was performed in the sagittal position: The number of slices $=128$, $\mathrm{TR}=2,530 \mathrm{~ms}, \mathrm{TE}=3.39 \mathrm{~ms}$, slice thickness $=1.33 \mathrm{~mm}$, zero-filling, $\mathrm{TI}=1,100 \mathrm{~ms}, \mathrm{FOV}=256 \times 256 \mathrm{~mm}^{2}$, acquisition matrix $=256 \times 192$, and $F A=7^{\circ}$. Parameters of $\mathrm{fMRI}$ in the resting state were obtained: The number of slices $=32$, slice thickness $=4 \mathrm{~mm}$, zero-filling, $\mathrm{TR}=2,000 \mathrm{~ms}, \mathrm{TE}=30$ $\mathrm{ms}, \mathrm{FOV}=220 \times 220 \mathrm{~mm}^{2}$, acquisition matrix $=64 \times 64$, and $\mathrm{FA}=90^{\circ}$, for a total of 7 minutes.

\section{Selection of Fiber Bundles}

Commissural fibers: Mental disorders, such as depression and anxiety, are associated with the destruction of the white matter fiber tracts associated with mood. ${ }^{14}$ The cingulum, fornix-fimbria, anterior commissure, and, to some extent, the corpus callosum are fiber bundles that connect these brain structures and therefore are thought to play a role in emotional processing.

Association fibers: By looking at the literature, recent studies have shown that the fasciculus uncinatus, the superior and interior longitudinal fasciculus, the interior 
occipitofrontal fasciculus, and the corpus callosum are involved in mental illness, Compared with non-anxiety patients, a lower FA is detected in anxiety patients. ${ }^{15,16}$

Projection fibers: In our early clinical study, DTI technology was used to preliminarily confirm the involvement of cerebellar in the occurrence of PSD. ${ }^{17}$ The intersected cortical fascicles mostly started from the frontal and parietal cortex and descended through the posterior limbs of the internal capsule, bypassing the front of the pons and reaching the contralateral cerebellar hemisphere, so it was believed that they were involved in the occurrence of PSD. We know that PSD is associated with many risk factors, including more severe dyskinesia, higher disability, and poorer social support networks, ${ }^{18}$ leading to speculation that corticospinal tract motor fibers are involved in PSD. Prethalamic radiation is the connecting fiber between the thalamus and the prefrontal lobe. As an important component of the corticothalamo-cortical loop, prethalamic radiation is mainly involved in the implementation and planning of complex behaviors. The damage of prethalamic radiation affects the normal activity of the brain.

\section{Processing of DTI Images}

Raw data obtained from DTI were uploaded to the Extended MR WorkSpace for post-processing and analysis using the DTI Studio software. The FA parameter maps were obtained after smooth de-noising. Fiber-tracking results were obtained using the fiber assignment by tracking, with the setting of $F A<0.25$. DTI images were fused with sequences of DWI, PWI, 3DT1, SWI, FLAIR, and MRA for reconstruction of transmission tracts, followed by observation of the damage of nerve fiber bundles at the lesion site. FA and numbers of lesioned nerve fiber bundles (lines) were recorded from three triplicate measurements.

\section{Statistical Analysis}

Statistical analysis was conducted using SAS 9.4 software package. Chi-square test were used for comparing counting data, and the results were expressed as a percentage. First, the measurement data were tested for normality. When they were in line with the normal distribution, one-way ANOVA was used for comparison among the three groups, and SNKq test was used for pair-wise comparison among the groups. A non-parametric test was used when it did not conform to normality, and the results were expressed as mean \pm standard deviation. The relationship between white matter fiber bundle disorder and depression scale score (HADM) was analyzed by Pearson's correlation coefficient. $P<0.05$ was considered as statistically significant.

\section{Drawing of the Forest Plots}

Stata (Version: 13.1) software was used to analyze the selected factors, and the odds ratio (OR) of each PSD risk factor was calculated, which was expressed as 95\% confidence interval (95\% CI). Finally, an intuitive forest map is drawn (Figure 1).

\section{Results \\ General Conditions}

General conditions of each subject, including baseline characteristics and clinical data, were compared at first. There was no significant differences in age, gender, marriage, educational degree, random blood sugar, blood pressure, history of coronary disease, or transient ischemic attack (TIA) among the PSD, N-PSD, and NORM group $(P>0.05)$ Notably, HAMD score was significantly higher in the PSD group than in the other groups $(P<0.05)$ (Table 4).

\section{Imaging Data \\ Comparison of Cerebral Infarction Volume and Infarction Side}

There were no statistically significant differences between the PSD group and the NPSD group in terms of lesion profile and cerebral infarction volume $(P>0.05)$ (Table 5).

\section{FA of White Matter Tracts}

We did not identify significant differences in FA of the right and left superior/inferior longitudinal fasciculus, the superior/inferior occipitofrontal fasciculus, the fasciculus uncinatus, the left crossed corticocerebellar tract, the left corticospinal tract, and the left anterior thalamic radiation among PSD, N-PSD, and NORM groups $(P>0.05)$. However, significant differences in FA of the right crossed corticocerebellar tract, the right corticospinal tract, and the right anterior thalamic radiation were detected among three groups $(P<0.05)$ (Tables 6-8).

\section{Lines of White Matter Tracts}

There were no significant differences in lines of the right and left superior/inferior longitudinal fasciculus, the superior/ inferior occipitofrontal fasciculus, the fasciculus uncinatus, 


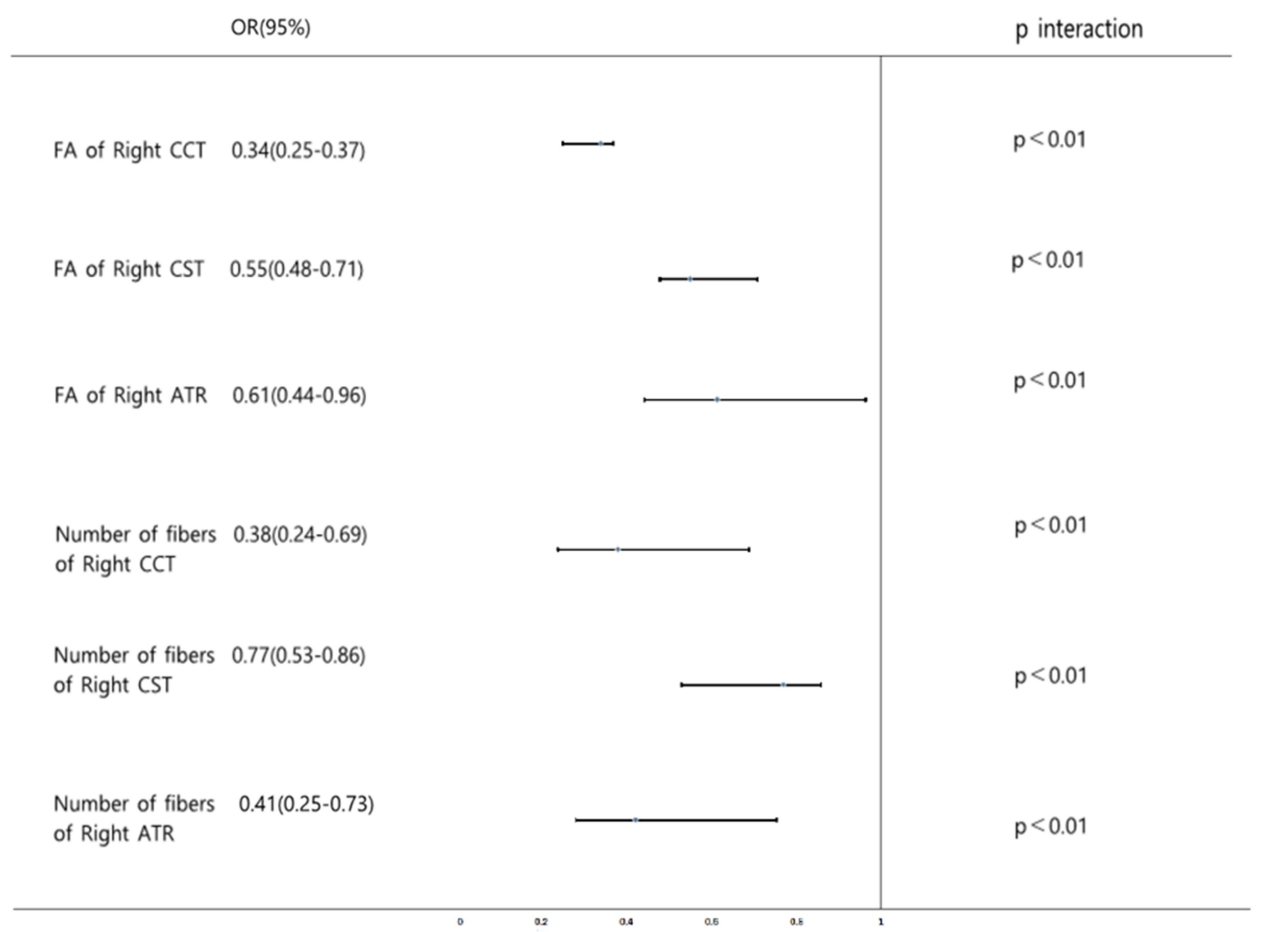

Figure I The Forest plot of the odds ratios (ORs) and 95\% confidence intervals (Cls) obtained from Stata's analysis of the six independent risk factors. The FA of right CCT, right CST, right ATR, and number of fibers of right CCT, right CST, right ATR are on the left side of the invalid line, which indicates a negative correlation with PSD.

the left crossed corticocerebellar tract, the left corticospinal tract and the left anterior thalamic radiation among the PSD, N-PSD, and NORM group $(P>0.05)$. We detected significant differences in lines of the right crossed corticocerebellar tract, the right corticospinal tract, and the right anterior thalamic radiation among three groups $(P<0.05)$. Compared with those of the N-PSD and NORM group, lines of the right crossed corticocerebellar tract, the right corticospinal tract and the right anterior thalamic radiation were statistically significant in the PSD group $(P<0.05)$ (Tables 9-11).

\section{Correlation Between FA of White Matter Tracts and HAMD Score in PSD Group}

Pearson's correlation test obtained negative correlations between FA of the right crossed corticocerebellar tract $(\mathrm{r}=0.586, P<0.05)$, the right corticospinal tract $(\mathrm{r}=0.793$,

Table 4 Comparison of Basic Data of Three Groups of Subjects

\begin{tabular}{|l|l|l|l|l|l|}
\hline Item & PSD Group & NPSD Group & NORM Group & F/ $\chi^{2}$ & $P$-value \\
\hline Age (years) & $53.4 \pm 9.8$ & $54.6 \pm 7.6$ & $53.2 \pm 8.4$ & 0.153 & 0.858 \\
Male/Female & $10 / 10$ & $9 / 11$ & $12 / 8$ & 0.934 & 0.627 \\
Education time (years) & $9.3 \pm 2.6$ & $8.8 \pm 2.4$ & $9.4 \pm 2.5$ & 0.330 & 0.720 \\
Diabetes [n (\%)] & $7(35.0)$ & $6(30.0)$ & $8(40.0)$ & 0.440 & 0.803 \\
Hypertension (HBP) [n(\%)] & $12(60.0)$ & $13(65.0)$ & $11(55.0)$ & 0.417 & 0.812 \\
Hyper lipidemia [n(\%)] & $9(45.0)$ & $10(50.0)$ & $8(40.0)$ & 0.404 & 0.817 \\
Coronary heart disease (CHD)[n(\%)] & $4(20.0)$ & $5(25.0)$ & $6(30.0)$ & 0.533 & 0.766 \\
TIA [n(\%)] & $8(40.0)$ & $10(50.0)$ & $8(40.0)$ & 0.543 & 0.762 \\
Initial NIHSS score & $6.85 \pm 1.81$ & $7.35 \pm 1.25$ & - & 1.017 & 0.316 \\
I4-day NIHSS score & $5.59 \pm 1.74$ & $2.86 \pm 1.08$ & - & 2.730 \\
HAMD score & $13.59 \pm 3.77$ & $2.44 \pm 1.8 I^{*}$ & $2.41 \pm 1.72 *$ & 121.930 & $<0.001$ \\
SDS standard score & $56.83 \pm 4.06$ & $28.84 \pm 5.47^{*}$ & $26.73 \pm 3.86^{*}$ & 276.311 \\
\hline
\end{tabular}

Notes: $* P<0.05$, compared with PSD group. 
Table 5 Comparison of Infarction Side and Infarction Volume of Three Groups of Subjects

\begin{tabular}{|l|l|l|l|l|l|}
\hline Item & $\begin{array}{l}\text { PSD } \\
\text { Group }\end{array}$ & $\begin{array}{l}\text { NPSD } \\
\text { Group }\end{array}$ & $\begin{array}{l}\text { NORM } \\
\text { Group }\end{array}$ & F/ $\chi^{2}$ & P-value \\
\hline $\begin{array}{l}\text { Infarction } \\
\text { side }\end{array}$ & $12 / 8$ & $9 / 11$ & $0 / 0$ & 0.902 & 0.342 \\
$\begin{array}{l}\text { Infarction } \\
\text { volume }\end{array}$ & $\begin{array}{l}4.24 \\
\pm 1.65\end{array}$ & $\begin{array}{l}4.16 \\
\pm 2.09\end{array}$ & - & 0.134 & 0.894 \\
\hline
\end{tabular}

$P<0.05)$, and the right anterior thalamic radiation $(\mathrm{r}=0.626$, $P<0.05$ ), and HAMD score in the PSD group (Figures 2-4).

\section{Correlation Between Lines of White Matter Tracts and HAMD Score in PSD Group}

Pearson's correlation test obtained negative correlations between lines of the right crossed corticocerebellar tract $(\mathrm{r}=0.533, P<0.05)$, the right corticospinal tract $(\mathrm{r}=0.642$, $P<0.05)$, and the right anterior thalamic radiation $(\mathrm{r}=0.524$, $P<0.05$ ), and HAMD score in the PSD group (Figures 5-7).

\section{Follow-Up After Discharge}

HAMD scores were followed up for each patient after discharge. The incidence of PSD peaked from the second month to the sixth month after stroke (Figure 8)

\section{DTT Images}

As images of MRI scanning and DTT revealed, nerve fiber bundles of the ipsilesional crossed corticocerebellar tract, the corticospinal tract, and the anterior thalamic radiation were damaged in PSD patients, and their lines were declined (Figure 9A-I). Images findings of nerve fiber lesions were consistent with the clinical evaluation on the depressive state of PSD patients.

Images of white matter tracts in PSD patients from the superior view (Figure 9A, D, and G), the posterior view (Figure 9B, E, and $\mathrm{H}$ ), the left side view (Figure 9C and F), and the posterior view (Figure 9I). (A-C) DTT images of the anterior thalamic radiation projected from the anterior nuclear group of the dorsal thalamus and the dorsal medial nucleus to the cingulated gyrus and the frontal lobe. The anterior limb of the internal capsule constitutes the anterior thalamic radiation, which connects the thalamus and the prefrontal lobe. Lines of the anterior thalamic radiation were significantly reduced, and its connection to surrounding brain tissues was separated (red arrow). FA of the ipsilesional anterior thalamic radiation was lower than that of the contralesional side. (D-F) DTT images of the crossed corticocerebellar tract extending from the frontal and parietal cortex (some from the inferior frontal gyrus), descending through the posterior limb of internal

Table 6 Comparison of FA of Commissural Fibers $(\bar{x} \pm S D)$

\begin{tabular}{|l|l|l|l|l|l|}
\hline Commissural Fibers & PSD Group & N-PSD Group & NORM Group & Statistics & P-value \\
\hline CPC & $0.641 \pm 0.116$ & $0.649 \pm 0.103$ & $0.651 \pm 0.097$ & 0.050 & 0.951 \\
ATC & $0.684 \pm 0.093$ & $0.676 \pm 0.087$ & $0.689 \pm 0.102$ & 0.097 & 0.908 \\
FRC & $0.668 \pm 0.075$ & $0.675 \pm 0.087$ & $0.671 \pm 0.086$ & 0.036 & 0.965 \\
\hline
\end{tabular}

Abbreviations: CPC, corpus callosum; ATC, anterior commissure; FRC, fornical commissure.

Table 7 Comparison of FA of Association Fibers ( $\bar{x} \pm$ SD)

\begin{tabular}{|c|c|c|c|c|c|}
\hline Association Fibers & PSD Group & N-PSD Group & NORM Group & Statistics & $P$-value \\
\hline Right SLF & $0.623 \pm 0.142$ & $0.615 \pm 0.057$ & $0.656 \pm 0.094$ & 0.86 & 0.43 \\
\hline Left SLF & $0.662 \pm 0.139$ & $0.694 \pm 0.069$ & $0.700 \pm 0.082$ & 0.81 & 0.45 \\
\hline Right ILF & $0.637 \pm 0.120$ & $0.650 \pm 0.090$ & $0.662 \pm 0.084$ & 0.31 & 0.73 \\
\hline Left ILF & $0.655 \pm 0.118$ & $0.642 \pm 0.094$ & $0.615 \pm 0.103$ & 2.98 & 0.23 \\
\hline Right SOF & $0.688 \pm 0.116$ & $0.670 \pm 0.082$ & $0.63 I \pm 0.105$ & 1.68 & 0.20 \\
\hline Left SOF & $0.647 \pm 0.087$ & $0.656 \pm 0.076$ & $0.67 I \pm 0.094$ & 1.04 & 0.60 \\
\hline Right IOF & $0.673 \pm 0.079$ & $0.663 \pm 0.086$ & $0.668 \pm 0.081$ & 0.06 & 0.94 \\
\hline Left IOF & $0.68 I \pm 0.085$ & $0.62 \pm 0.085$ & $0.646 \pm 0.089$ & 5.03 & 0.08 \\
\hline Right FN & $0.673 \pm 0.089$ & $0.638 \pm 0.079$ & $0.669 \pm 0.086$ & 1.03 & 0.36 \\
\hline Left FN & $0.664 \pm 0.093$ & $0.661 \pm 0.092$ & $0.64 I \pm 0.105$ & 0.33 & 0.72 \\
\hline
\end{tabular}

Abbreviations: SLF, superior longitudinal fasciculus; ILF, inferior longitudinal fasciculus; SOF, superior occipitofrontal fasciculus; IOF, interior occipitofrontal fasciculus; FN, fasciculus uncinatus. 
Table 8 Comparison of FA of Projection Fibers $(\bar{x} \pm$ SD)

\begin{tabular}{|l|l|l|l|l|l|}
\hline Projection Fibers & PSD Group & N-PSD Group & NORM Group & Statistics & P-value \\
\hline Right CCT & $0.528 \pm 0.062^{\mathrm{a}}$ & $0.681 \pm 0.069^{\mathrm{b}}$ & $0.695 \pm 0.072^{\mathrm{b}}$ & 0.85 & $<0.01$ \\
Left CCT & $0.672 \pm 0.095$ & $0.628 \pm 0.101$ & $0.635 \pm 0.078$ & 1.31 & 0.28 \\
Right CST & $0.569 \pm 0.078^{\mathrm{a}}$ & $0.645 \pm 0.083^{\mathrm{b}}$ & $0.650 \pm 0.073^{\mathrm{b}}$ & 0.76 & $<0$ \\
Left CST & $0.649 \pm 0.084$ & $0.631 \pm 0.086$ & $0.697 \pm 0.093$ & 3.03 & 0.06 \\
Right ATR & $0.573 \pm 0.102^{\mathrm{a}}$ & $0.647 \pm 0.087^{\mathrm{b}}$ & $0.677 \pm 0.073^{\mathrm{b}}$ & 1.39 & $<0.01$ \\
Left ATR & $0.635 \pm 0.104$ & $0.645 \pm 0.099$ & $0.672 \pm 0.090$ & 0.76 & 0.47 \\
\hline
\end{tabular}

Notes: Pairwise comparison between groups was conducted by SNK-q test. There is statistical difference, $b>a$.

Abbreviations: CCT, crossed corticocerebellar tract; CST, corticospinal tract; ATR, anterior thalamic radiation.

Table 9 Comparison of Lines of Commissural Fibers $(\bar{x} \pm S D)$

\begin{tabular}{|l|l|l|l|l|l|}
\hline Commissural Fibers & PSD Group & N-PSD Group & NORM Group & Statistics & P-value \\
\hline CPC & $447.5 \pm 146.81$ & $456.81 \pm 159.67$ & $450.19 \pm 139.92$ & 0.021 & 0.980 \\
ATC & $459.17 \pm 137.32$ & $447.74 \pm 142.77$ & $467.08 \pm 146.13$ & 0.094 & 0.911 \\
FRC & $369.67 \pm|4| .41$ & $381.64 \pm 151.28$ & $374.81 \pm 149.36$ & 0.033 & 0.967 \\
\hline
\end{tabular}

Abbreviations: CPC, corpus callosum; ATC, anterior commissure; FRC, fornical commissure.

Table 10 Comparison of Lines of Association Fibers $(\bar{x} \pm S D)$

\begin{tabular}{|c|c|c|c|c|c|}
\hline Association Fibers & PSD Group & N-PSD Group & NORM Group & Statistics & $P$-value \\
\hline Right SLF & $4 \mid 3.45 \pm 178.56$ & $387.95 \pm 145.15$ & $439.85 \pm 183.34$ & 0.47 & 0.63 \\
\hline Left SLF & $367.80 \pm 181.23$ & $340.15 \pm 147.72$ & $390.60 \pm 184.54$ & 0.43 & 0.65 \\
\hline Right ILF & $444.30 \pm 149.13$ & $387.10 \pm 165.85$ & $412.40 \pm 137.19$ & 0.72 & 0.49 \\
\hline Left ILF & $400.70 \pm 147.80$ & $341.55 \pm 171.79$ & $370.15 \pm 136.52$ & 0.75 & 0.48 \\
\hline Right SOF & $460.25 \pm 132.75$ & $435.60 \pm 157.00$ & $463.00 \pm 152.59$ & 0.21 & 0.81 \\
\hline Left SOF & $410.45 \pm 124.06$ & $379.85 \pm 163.16$ & $415.40 \pm 154.83$ & 0.34 & 0.72 \\
\hline Right IOF & $368.30 \pm 150.59$ & $415.30 \pm 152.35$ & $416.00 \pm 164.32$ & 0.62 & 0.54 \\
\hline Left IOF & $316.00 \pm 147.77$ & $369.70 \pm|52.4|$ & $367.15 \pm 164.26$ & 0.76 & 0.47 \\
\hline Right FN & $465.10 \pm 156.18$ & $448.20 \pm 158.35$ & $392.85 \pm 150.92$ & 2.44 & 0.23 \\
\hline Left FN & $416.05 \pm 158.36$ & $395.15 \pm|5| .73$ & $353.75 \pm 143.48$ & 0.88 & 0.42 \\
\hline
\end{tabular}

Abbreviations: SLF, superior longitudinal fasciculus; ILF, inferior longitudinal fasciculus; SOF, superior occipitofrontal fasciculus; IOF, interior occipitofrontal fasciculus; FN, fasciculus uncinatus.

Table I I Comparison of Lines of Projection Fibers $(\bar{x} \pm$ SD)

\begin{tabular}{|c|c|c|c|c|c|}
\hline Projection Fibers & PSD Group & N-PSD g & NORM Group & Statistics & $P$-value \\
\hline Right CCT & $319.80 \pm 56.8 \mathrm{I}^{\mathrm{a}}$ & $450.90 \pm 126.02^{b}$ & $398.15 \pm 156.12^{b}$ & 0.68 & $<0.01$ \\
\hline Left CCT & $388.00 \pm 166.74$ & $395.70 \pm 125.68$ & $346.10 \pm 153.63$ & 0.64 & 0.53 \\
\hline Right CST & $336.25 \pm 34.95^{\mathrm{a}}$ & $425.90 \pm 164.66^{b}$ & $461.65 \pm 152.30^{b}$ & 1.23 & $<0.01$ \\
\hline Left CST & $438.35 \pm 103.37$ & $360.00 \pm 165.35$ & $401.45 \pm 153.62$ & 1.50 & 0.23 \\
\hline Right ATR & $349.80 \pm 149.10^{a}$ & $454.40 \pm 162.06^{b}$ & $502.65 \pm 125.06^{b}$ & 3.89 & $<0.01$ \\
\hline Left ATR & $311.50 \pm 166.55$ & $375.70 \pm 180.43$ & $449.15 \pm 130.73$ & 3.68 & 0.03 \\
\hline
\end{tabular}

Notes: Pairwise comparison between groups was conducted by SNK-q test. There is statistical difference, $b>a$.

Abbreviations: CCT, crossed corticocerebellar tract; CST, corticospinal tract; ATR, anterior thalamic radiation.

capsule, bypassing the anterior pontine, and terminating on the contralateral cerebellar hemisphere. Lines of the crossed corticocerebellar tract were significantly reduced, and its connection to surrounding brain tissues was separated (red arrow). FA of the ipsilesional corticocerebellar tract was lower than that of the contralesional side. (G-I) DTT images of the corticospinal tract that was mostly projected to the cortex of the parietal 


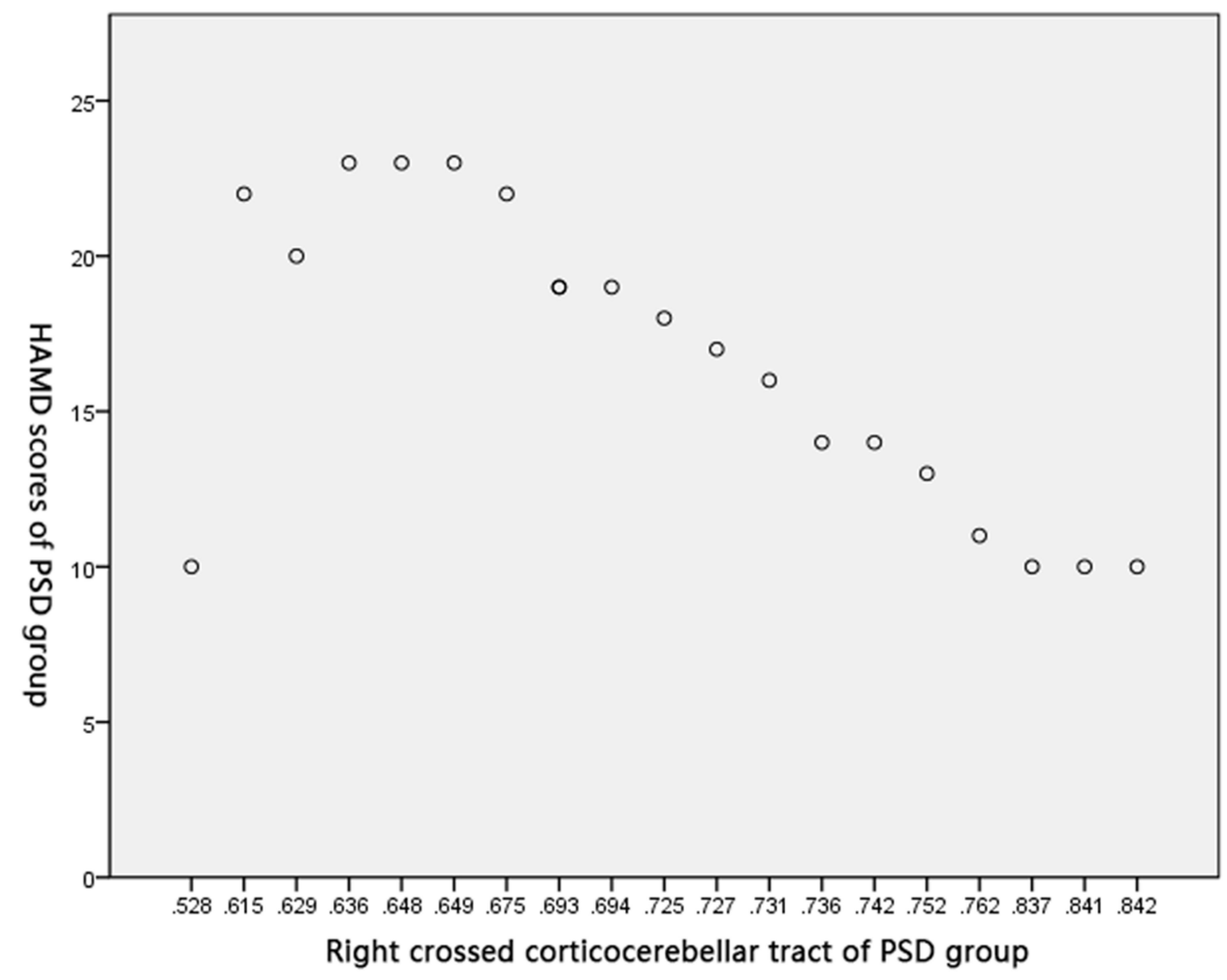

Figure 2 Correlation between FA of the right crossed corticocerebellar tract and HAMD score in PSD group.

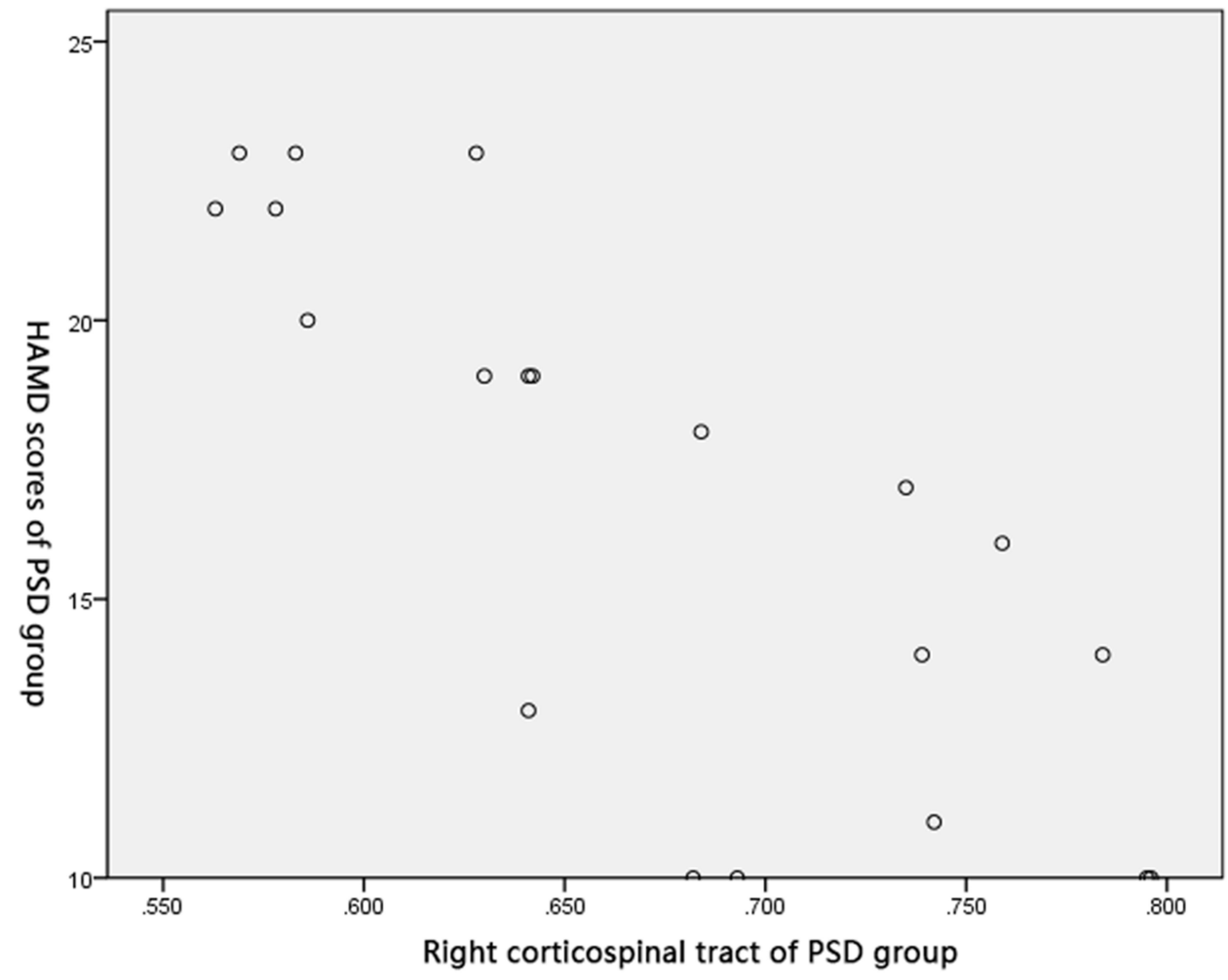

Figure 3 Correlation between FA of the right corticospinal tract and HAMD score in PSD group. 


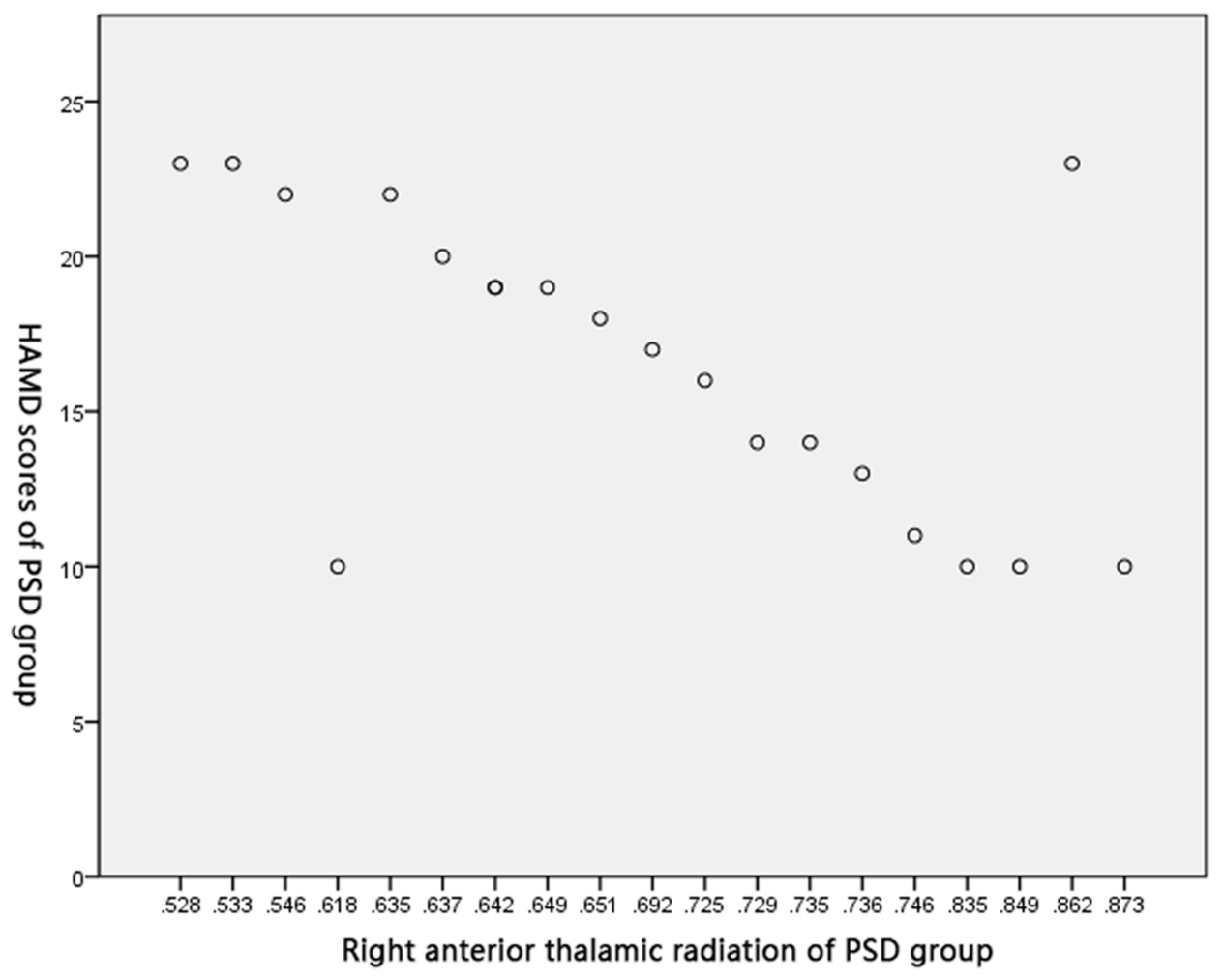

Figure 4 Correlation between FA of the right anterior thalamic radiation and HAMD score in PSD group.

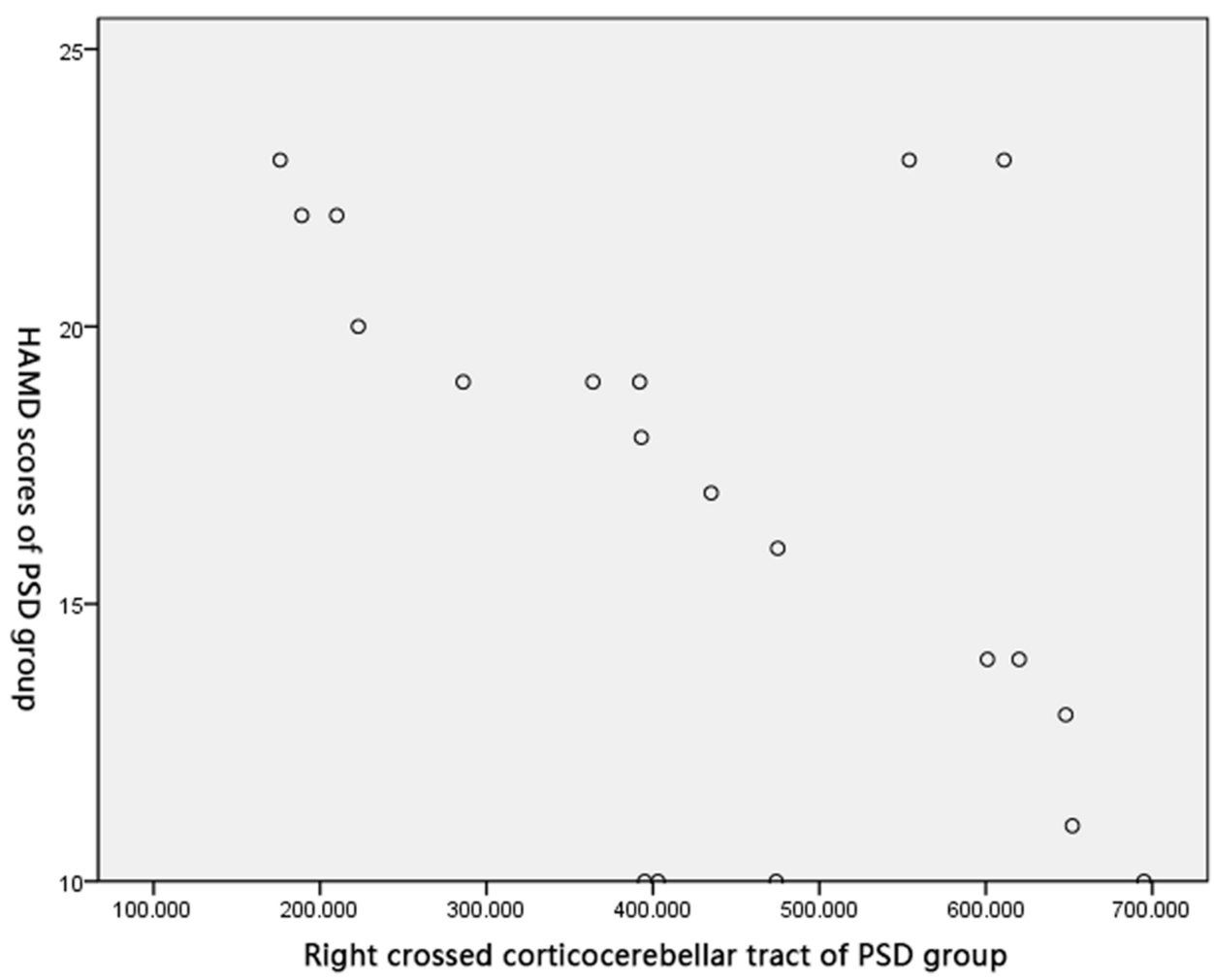

Figure 5 Correlation between lines of the right crossed corticocerebellar tract and HAMD score in PSD group. 


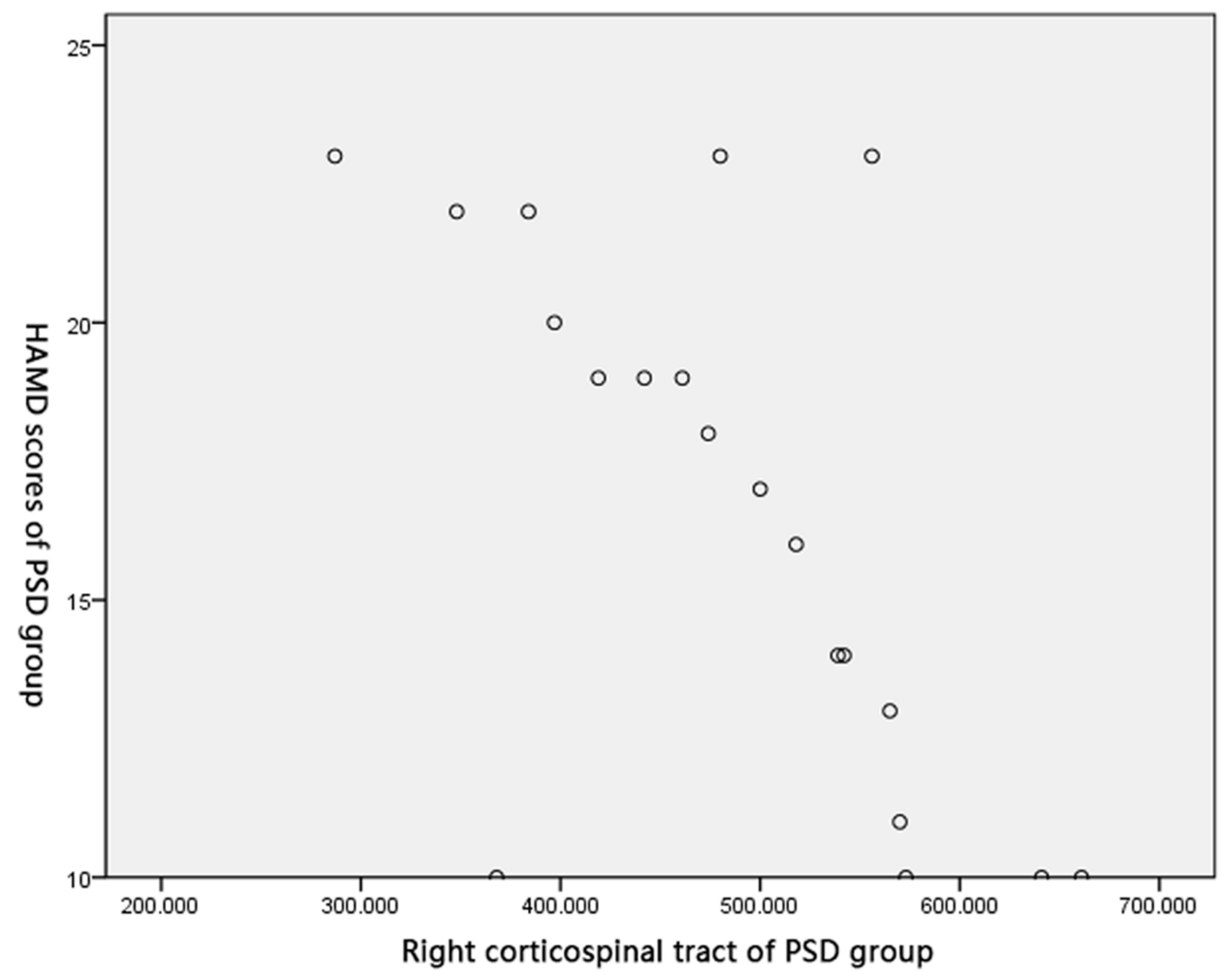

Figure 6 Correlation between lines of the right corticospinal tract and HAMD score in PSD group.

lobe and the occipital lobe, and the small part was projected to the lateral margin of the corpus callosum. Lines of the corticospinal tract were significantly reduced, and its connection to surrounding brain tissues was separated (red arrow). FA of the ipsilesional corticospinal tract was lower than that of the contralesional side.

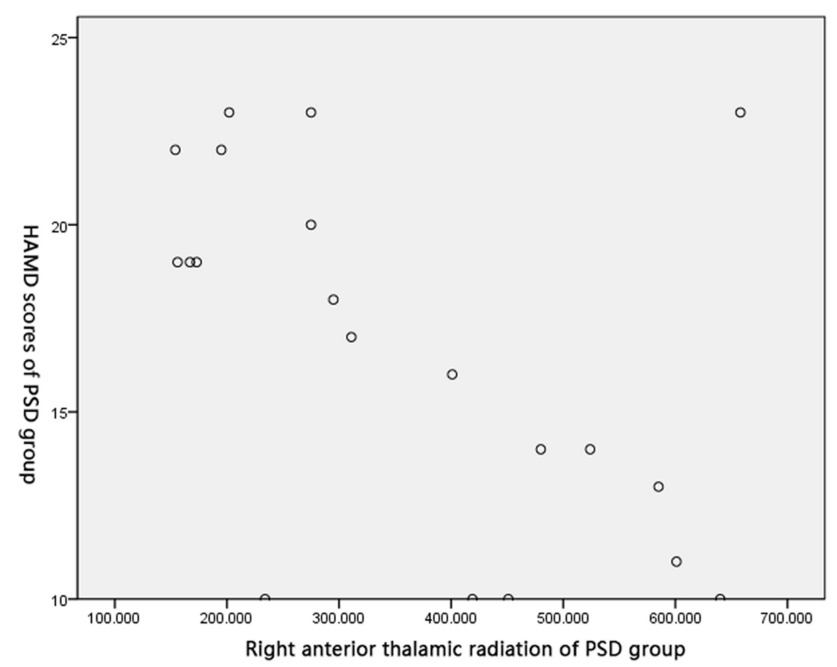

Figure 7 Correlation between lines of the right anterior thalamic radiation and HAMD score in PSD group.

\section{Discussion}

PSD is a frequent complication secondary to stroke, featuring high incidence $(>80 \%)$, high mortality, and high disability. So far, the pathogenesis of PSD remains unclear, and effective prevention and treatment drugs are lacking.

In the present study, DTT was applied in each subject for examining white matter tracts. DTT is a novel technique progressed from diffusion tensor imaging (DTI). Microstructure of brain tissue and integrity of white matter tracts can be reflected by FA and number of nerve fiber bundles. The white matter of the brain is composed of a large number of nerve fiber bundles responsible for emotional and cognitive functions, which can be classified into three categories: i) Commissural fibers, including the corpus callosum, the fornix and the anterior commissure; ii) Association fibers, including the superior and interior longitudinal fasciculus, the occipitofrontal fasciculus, and the fasciculus uncinatus; iii) Projection fibers, including the crossed corticocerebellar tract, the anterior thalamic radiation, the corticospinal tract, and the corticonuclear tract. ${ }^{19}$ To our knowledge, studies about the correlation between white matter tracts and PSD have been rarely reported.

Our findings uncovered that, compared to those in the NORM group, FA and lines of white matter tracts dropped 


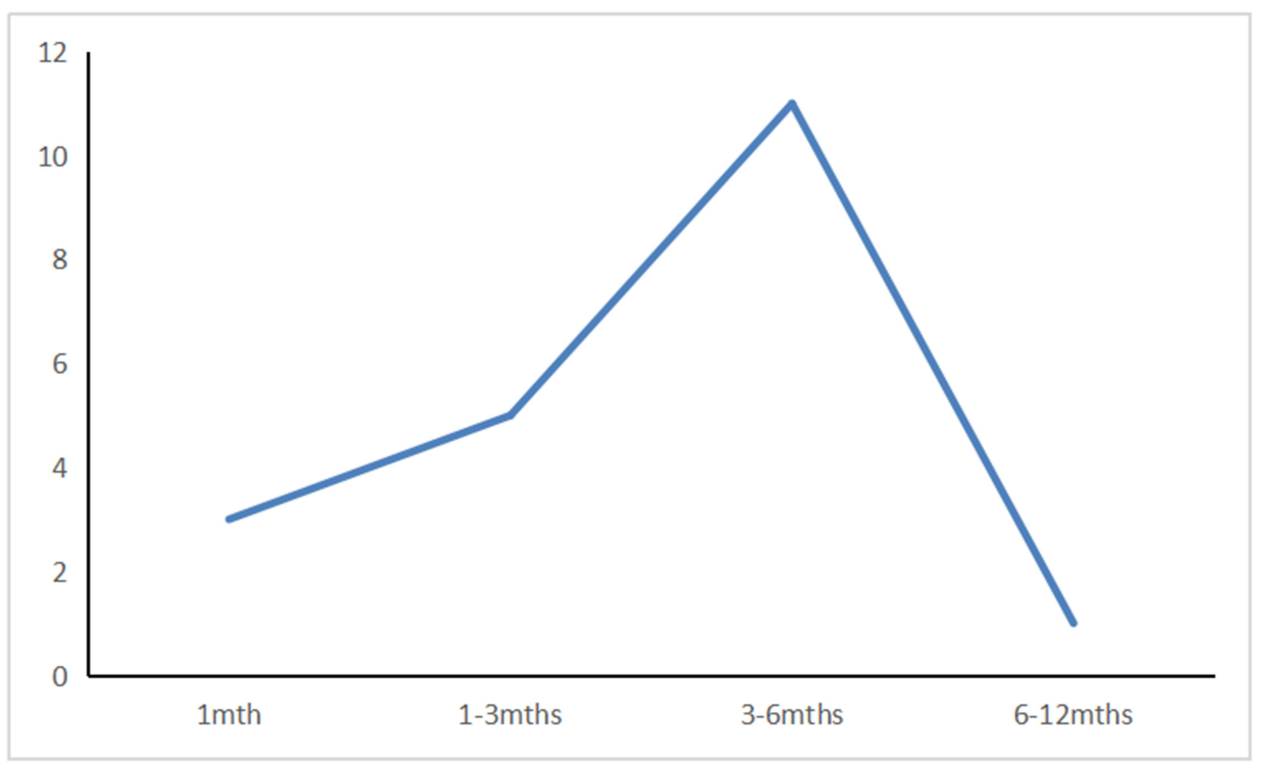

Figure 8 The relationship between the number of cases and time.

in the PSD and N-PSD group, more prominently in the former group. In addition, the drop in PSD patients had negative correlations to HAMD scores. It is suggested that the crossed corticocerebellar tract is involved in the development of PSD. The crossed corticocerebellar tract originates from the frontal and parietal cortex, descends through the posterior limb of the internal capsule, and terminates on the contralateral cerebellar hemisphere after bypassing the anterior pontine. The frontal lobe is an important part of the emotional network. ${ }^{20}$ Middleton and Strick $^{21}$ conducted an analysis on non-human primate animals, finding the partial output of the basal ganglia neurons to the prefrontal cortex. Lesions in the basal ganglia may damage projection fibers to the frontal lobe, which further causes affective disorders. As a result, we speculated that the crossed corticocerebellar tract was involved in the development of PSD, because of its correlation to crossed cerebellar diaschisis (CCD). CCD impairs cerebellar functions by reducing the cerebellar metabolism in the contralateral distant region via the synaptic connection between brain lesions in any part of the basal ganglia and the cerebellum. The research conducted by $\mathrm{Li}$ et al supported the involvement of the cerebellum in PSD, which is consistent with our findings. Kim et $\mathrm{al}^{22}$ proposed that fibrous connections and structure of the cerebellum in schizophrenia patients are changed and related to the clinical symptoms. Inconsistent with our results, Magnotta et $\mathrm{al}^{23}$ identified obvious disorders of white matter tracts of the superior cerebellar peduncle. In this paper, we did not detect FA changes in the superior cerebellar peduncle of PSD patients, which could be explained by the selective bias of the subjects. In addition, negative correlations were detected between changes of FA and lines of the ipsilesional crossed corticocerebellar tract, and HAMD scores in PSD patients, highlighting the importance of the crossed corticocerebellar tract.

Moreover, we detected that FA and lines of white matter tracts of the ipsilesional anterior thalamic radiation declined in PSD and NPSD patients, more prominently in the PSD group. This decline was negatively correlated to HAMD scores. It is suggested that anterior thalamic radiation was also involved in the development of PSD. The anterior thalamic radiation contains association fibers projected from the anterior nuclear group of the dorsal thalamus and the dorsal medial nucleus to the cingulated gyrus and the frontal lobe. The anterior limb of the internal capsule is constituted of the anterior thalamic radiation, which connects the thalamus and the prefrontal lobe. ${ }^{24}$ As a vital component of the cortico-striatal-thalamic-cortical loop (CSTC), the anterior thalamic radiation is responsible for planning and executing complex behaviors. Hence, a lesion in the anterior thalamic radiation significantly disrupts normal brain activities. Changes in the anterior thalamic radiation lead to the development of depressive disorder. ${ }^{25}$ Karlsgodt et al ${ }^{26}$ analyzed that in subjects at a high risk of major depression, FA is significantly low in their right anterior thalamic radiation, and closely relate to low-level social functions. So far, the correlation between 


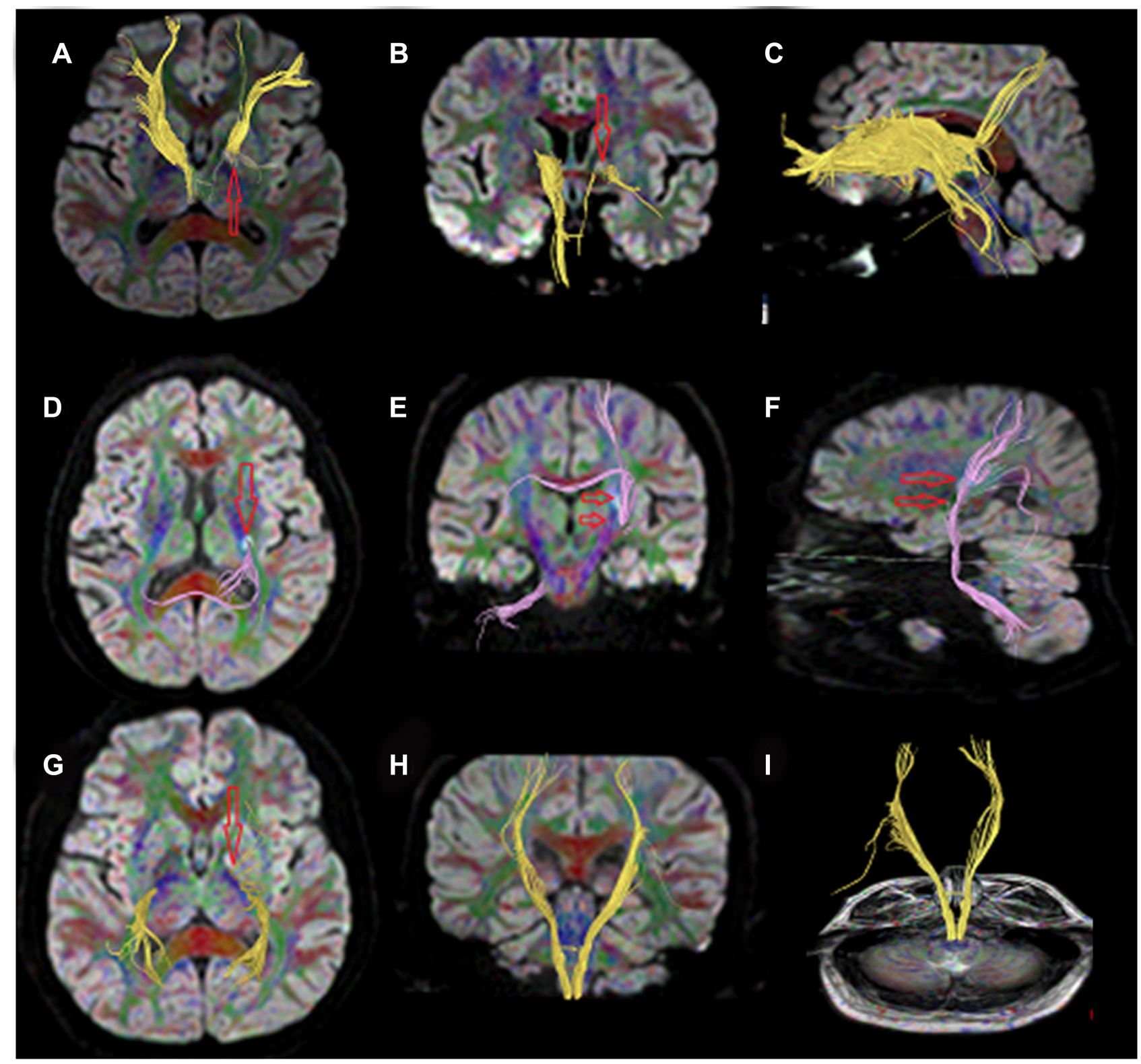

Figure 9 (A-I) DTT image depicting declines in FA and lines of white matter tracts in PSD patients.

the anterior thalamic radiation and PSD has been merely explored. Thalamic radiations are made of the bidirectional fibers between the thalamus and the cerebral cortex. Most of the regions joining the thalamus with the cerebral cortex take on four fan-shaped appearances (anterior, superior, posterior, and inferior views). In particular, the posterior thalamic radiation connects the occipital cortex, the posterior parietal cortex, and the posterior thalamus. A DTI study in patients with major depressive disorder (MDD) uncovered that the posterior thalamic radiation is closely related to facial expression recognition in MDD patients. ${ }^{16}$ The above experimental findings further supported that the thalamic radiation participated in the development of PSD.

PSD exerts adverse effects on emotional functions and daily activities. Our results demonstrated that FA and lines of white matter tracts in the ipsilesional corticospinal tract were significantly declined in the PSD and NPSD group than in the NORM group, and the declines were more obvious in PSD patients. Meanwhile, their reductions were negatively correlated to HAMD scores, suggesting the involvement of the corticospinal tract in the development of PSD. The corticospinal tract starts from the middle and upper parts of the anterior central gyrus and the 
interior paracentral lobule, and terminates on motor neurons in the anterior horn of spinal cord. A reduction of FA is detected in the corticospinal tract of patients with schizophrenia. ${ }^{16,27}$ Chhetry et $\mathrm{al}^{28}$ interviewed depression patients using $\omega-3$ polyunsaturated fatty acids ( $\omega$-3PUFA). Inconsistent with our findings, they suggested that the decrease of depression severity is correlated to increased FA in the left corticospinal tract. Differences in the location of the stroke lesion may explain the inconsistent conclusion.

In this study, we did not find changes in the FA value and the number of fiber bundles in the corpus callosum, Fornical commissure, Anterior commissure, and superior longitudinal fasciculus, inferior longitudinal fasciculus superior occipitofrontal fasciculus, and interior occipitofrontal fasciculus, which were related to the selection of infarct site.

Several limitations in this study should not be neglected. First of all, the sample size of subjects was relatively small. Secondly, In the future, a larger sample size with high-quality examinations are required to validate our findings. Patients with poor MRIs had more neurological problems, which can lead to secondary depression. $\mathrm{Ng}$ et $\mathrm{al}^{29}$ suggested that in the course of Parkinson's disease, patients are prone to depression, anxiety, and other negative emotions, which further reduces the quality-of-life of the patients. Further research on secondary depression is needed.

Taken together, this study for the first time detected that the ipsilesional crossed corticocerebellar tract, the corticospinal tract, and the anterior thalamic radiation are lesioned in PSD patients and significantly linked to depressive state. Our findings provide theoretical references for identifying the pathogenesis of PSD.

\section{Acknowledgments}

This work was supported by Project No. jytqn201707, study on the relationship between ET gene polymorphism and cerebral infarction, youth fund project of Liaoning Provincial Department of education/Project No. jytqn201707, study on the relationship between ET gene polymorphism and cerebral infarction, youth fund project of Liaoning Provincial Department of education/ Experimental Study on functional changes of cerebellar neural network in autism (No: jytjczr201903).

\section{Disclosure}

The authors report no conflicts of interest for this work.

\section{References}

1. Gawronski DW, Reding MJ. Post-stroke depression: an update. Curr Atheroscler Rep. 2001;3(4):307-312. doi:10.1007/s11883-001-0024-9

2. Campbell S, MacQueen G. An update on regional brain volume differences associated with mood disorders. Curr Opin Psychiatry. 2006;19(1):25-33. doi:10.1097/01.yco.0000194371.47685.f2

3. Honey CJ, Sporns O, Cammoun L, et al. Predicting human resting-state functional connectivity from structural connectivity. Proc Natl Acad Sci U S A. 2009;106(6):2035-2040. doi:10.1073/ pnas.0811168106

4. Taylor WD, Hsu E, Krishnan KR, MacFall JR. Diffusion tensor imaging: background, potential, and utility in psychiatric research. Biol Psychiatry. 2004;55(3):201-207. doi:10.1016/j.biopsych.2003.07.001

5. Beaulieu C. The basis of anisotropic water diffusion in the nervous system - a technical review. NMR Biomed. 2002;15(7-8):435-455. doi:10.1002/nbm.782

6. Mamata H, Mamata Y, Westin CF, et al. High-resolution line scan diffusion tensor MR imaging of white matter fiber tract anatomy. AJNR Am J Neuroradiol. 2002;23(1):67-75.

7. Shimony JS, McKinstry RC, Akbudak E, et al. Quantitative diffusion-tensor anisotropy brain MR imaging: normative human data and anatomic analysis. Radiology. 1999;212(3):770-784. doi:10.1148/radiology.212.3.r99au51770

8. Jang SH, Chang CH, Lee J, Kim CS, Seo JP, Yeo SS. Functional role of the corticoreticular pathway in chronic stroke patients. Stroke. 2013;44(4):1099-1104. doi:10.1161/STROKEAHA.111.000269

9. Danielian LE, Iwata NK, Thomasson DM, Floeter MK. Reliability of fiber tracking measurements in diffusion tensor imaging for longitudinal study. Neuroimage. 2010;49(2):1572-1580. doi:10.1016/j. neuroimage.2009.08.062

10. Seo JP, Kwon YH, Jang SH. Mini-review of studies reporting the repeatability and reproducibility of diffusion tensor imaging. Investig Magn Reson Imaging. 2019;23(1):26-33. doi:10.13104/ imri.2019.23.1.26

11. Wang X. Diagnostic of various cerebral vascular diseases. Chin J Neurol. 1996;029:379-380.

12. Wu RH, Li Q, Tan Y, Liu XY, Huang J. Depression in silent lacunar infarction: a cross-sectional study of its association with location of silent lacunar infarction and vascular risk factors. Neurol Sci. 2014;35 (10):1553-1559. doi:10.1007/s10072-014-1794-5

13. Li Y. Prevalence rate and impact factors of ischemic post-stroke depression. Chin J Modern Drug Appl. 2011;5:18.

14. Shizukuishi T, Abe O, Aoki S. Diffusion tensor imaging analysis for psychiatric disorders. Magn Reson Med Sci. 2013;12(3):153-159. doi:10.2463/mrms.2012-0082

15. Xia W, Zhou R, Zhao G, et al. Abnormal white matter integrity in Chinese young adults with first-episode medication-free anxious depression: a possible neurological biomarker of subtype major depressive disorder. Neuropsychiatr Dis Treat. 2018;14:2017-2026. doi:10.2147/NDT.S169583

16. Liao Y, Huang X, Wu Q, et al. Is depression a disconnection syndrome? Meta-analysis of diffusion tensor imaging studies in patients with MDD. J Psychiatry Neurosci. 2013;38(1):49-56. doi:10.1503/ jpn. 110180

17. Li M, Sui R, Zhang F, Zhao M, Li G, Zhang L. Clinical study on the diffusion tensor imaging of cerebellum in patients with post-stroke depression. J Apoplexy Nerv Dis. 2016;33:397-401.

18. Carod-Artal FJ. Post-stroke depression (I). epidemiology, diagnostic criteria and risk factors. Rev Neurol. 2006;42(3):169-175.

19. Sheline YI, Price JL, Vaishnavi SN, et al. Regional white matter hyperintensity burden in automated segmentation distinguishes late-life depressed subjects from comparison subjects matched for vascular risk factors. Am $J$ Psychiatry. 2008;165(4):524-532. doi:10.1176/appi.ajp.2007.07010175 
20. Price JL, Drevets WC. Neural circuits underlying the pathophysiology of mood disorders. Trends Cogn Sci. 2012;16(1):61-71. doi:10.1016/j.tics.2011.12.011

21. Middleton FA, Strick PL. Anatomical evidence for cerebellar and basal ganglia involvement in higher cognitive function. Science. 1994;266(5184):458-461. doi:10.1126/science.7939688

22. Kim DJ, Kent JS, Bolbecker AR, et al. Disrupted modular architecture of cerebellum in schizophrenia: a graph theoretic analysis. Schizophr Bull. 2014;40(6):1216-1226. doi:10.1093/schbul/ sbu059

23. Magnotta VA, Adix ML, Caprahan A, Lim K, Gollub R, Andreasen NC. Investigating connectivity between the cerebellum and thalamus in schizophrenia using diffusion tensor tractography: a pilot study. Psychiatry Res. 2008;163(3):193-200. doi:10.1016/j. pscychresns.2007.10.005

24. Lisiecka DM, Carballedo A, Fagan AJ, Ferguson Y, Meaney J, Frodl T. Recruitment of the left hemispheric emotional attention neural network in risk for and protection from depression. J Psychiatry Neurosci. 2013;38(2):117-128. doi:10.1503/jpn.110188
25. Macoveanu J, Knorr U, Skimminge A, et al. Altered reward processing in the orbitofrontal cortex and hippocampus in healthy first-degree relatives of patients with depression. Psychol Med. 2014;44(6):1183-1195. doi:10.1017/S0033291713001815

26. Karlsgodt $\mathrm{KH}$, Niendam TA. Bearden CE, et al White Mater Integrity and Prediction of Social and Role Functioning in Subjects at UItr-High Risk for Psychosis [J]. Biological psychiary. 2009;66(6):562-569.

27. Chen G, Hu X, Li L, et al. Disorganization of white matter architecture in major depressive disorder: a meta-analysis of diffusion tensor imaging with tract-based spatial statistics. Sci Rep. 2016;6(1):21825. doi:10.1038/srep21825

28. Chhetry BT, Hezghia A, Miler JM, et al. Omega-3 polyunsaturated fatty acid supplementation and white mattrchanges in majordepression[J]. J Psychiatr Res. 2016;75:6574.

29. Ng A, Chander RJ, Tan LC, Kandiah N. Influence of depression in mild Parkinson's disease on longitudinal motor and cognitive function. Parkinsonism Relat Disord. 2015;21(9):1056-1060. doi:10.1016/j.parkreldis.2015.06.014
Neuropsychiatric Disease and Treatment

\section{Publish your work in this journal}

Neuropsychiatric Disease and Treatment is an international, peerreviewed journal of clinical therapeutics and pharmacology focusing on concise rapid reporting of clinical or pre-clinical studies on a range of neuropsychiatric and neurological disorders. This journal is indexed on PubMed Central, the 'PsycINFO' database and CAS, and
Dovepress

is the official journal of The International Neuropsychiatric Association (INA). The manuscript management system is completely online and includes a very quick and fair peer-review system, which is all easy to use. Visit http://www.dovepress.com/testimonials.php to read real quotes from published authors. 